УДК 37:316.48(07)

DOI:

Вікторія Стинська, доктор педагогічних наук, професор, професор кафедри педагогіки та освітнього менеджменту імені Богдана Ступарика ДВНЗ "Прикарпатський національний університет імені Василя Стефаника" Зіновій Ящишин, кандидат медичних наук, дочент кафедри патологічної фізіології Івано-Франківського національного медичного університету

Олена Янків, асистент кафедри патологічної фізіологіi Івано-Франківського національного медичного університету Володимир Стинський, студент 2 курсу спеціальності "Інженерія програмного забезпечення" ДВНЗ "Прикарпатський начіональний університет імені Василя Стефаника"

\title{
ВИКОРИСТАННЯ ЦИФРОВИХ ОСВІТНІХ ПЛАТФОРМ У ПРОЦЕСІ ПІДГОТОВКИ МАЙБУТНІХ ВИКЛАДАЧІВ ЗВО
}

Статтю присвячено актуальній проблемі цифрофізачії освіти та розвитку одного з ї̈ нових форматів - масового навчання за допомогою освітніх платформ у процесі підготовки майбутніх викладачів 3 ВО.

Встановлено, щзо базовими вимогами до підготовки майбутніх фахівців $3 В О$ є не тільки розвинені комунікативні вміння й навички, самоконтроль і самооцінка, а й інформаційна складова професійної підготовки. А стрімкий перехід $3 B О$ на дистанційну форму навчання актуалізував питання готовності цифрових технологій забезпечити реалізачію повноцінного освітнього процесу за допомогою адекватних інструментів, ресурсів та сервісів.

Ключові слова: дистанційне навчання; електронні освітні платформи; масові онлайн курси; циифровізація освіти.

Jim. 7.

Viktoriia Stynska, Doctor of Science (Pedagogy), Professor, Professor of the Pedagogy and Educational Management Department named after Bohdan Stuparyk SHEE "Vasyl Stefanyk Precarpathian National University" Zinovii Yashchyshyn, Ph.D.(Medicine), Associate Professor of the Pathological Physiology Department Ivano-Frankivsk National Medical University Olena Yankiv, Assistant of the Pathological Physiology Department Ivano-Frankivsk National Medical University Volodymyr Stynskyi, the 2nd year Student majoring in "Software Engineering" SHEE "Vasyl Stefanyk Precarpathian National University"

\section{DIGITALEDUCATION PLATFORM USING IN PREPARATION PROCESS OF FUTURE HEI TEACHER}

The article is devoted to the topical problem of digitalization of education and the development of one of its new formats - massive education with the educational platform assist in the process of the future HEI teacher preparation.

It is established that the basic requirements for the future HEI teacher preparation, are not only developed communicative content and skills, self-control and self-assessments and the information component of professional preparation.

The rapid HEI transition to the distance education form actualizes the question of readiness of digital technologies to ensure full educational process realization with the adequate tools help, resources and services.

Educational platforms are characterized: for video conferences and online meetings (Zoom, Microsoft Teams, Google Meet, Skype, Discord); to place electronic materials (Moodle, Google Classroom); to create presentations, infographics and graphic design (Canva, Calameo, Crello, Desygner, Prezi.com, Beautiful.ai, Easel.ly, Genially); to create charts and graphs (Dygraphs, Excel, Infogram, Plotly, VisualizeFree, Fusiontables); to create video lectures with the ability to apply video tests or other tasks (TEDEd, FlipGrid); for texts, tasks creation and knowledge test (Kahoot, Quizel, Learningapps, Linoit, Classtime, Online test pad, Triventy.com, Quizlet.com, Flippity); to create selections of materials (Padlet, Wakelet, Miro).

It is concluded, that the distance learning services using will allow to increase and improve the efficiency of the HEI educational process, to make educational tasks way more interesting, diverse, attractive for students and to provide the basic paradigm of "knowledge economy" - lifelong learning.

Keywords: distance education; digital educational platforms; web-services; video conferencing, HEI teacher.

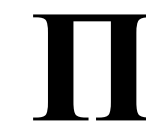

остановка проблеми. На сучасному етапі технологічна й інформаційна глобалізація диктує міжнародні

В. Стинська, 3. Ящишин, О. Янків,

В. Стинський, 2021 стандарти та вимоги до кваліфікації фахівців i, відповідно, до національних систем підготовки кадрів. Вища ланка освітньої системи повинна

Молодь і ринок №5-6 (191-192), 2021 


\section{ВИКОРИСТАННЯ ЦИФРОВИХ ОСВІТНІХПЛАТФОРМ У ПРОЦЕСІПІДГОТОВКИ МАЙБУТНІХ ВИКЛАДАЧІВ ЗВО}

забезпечити підготовку “фахівців, здатних забезпечити перехід від індустріального до інформаційно-технологічного суспільства через новаторство у навчанні, вихованні та науковометодичній роботі" [6].

У зв'язку з коронавірусною пандемією очевидною перевагою кожного випускника стає інформаційна складова професійної підготовки. Зокрема, базовими вимогами до фахівців $є$ розвинені комунікативні вміння й навички, самоконтроль і самооцінка, співпраця й використання IT на рівні досвідченого користувача. Відповідність цим критеріям може зробити випускника ЗВО більш конкурентоспроможним.

Відтак, стрімкий перехід ЗВО на дистанційну форму навчання актуалізував питання готовності цифрових технологій забезпечити реалізацію повноцінного освітнього процесу за допомогою адекватних інструментів, ресурсів та сервісів.

Аналіз останніх досліджень і публікацій Огляд психолого-педагогічної літератури показав, що на сучасному етапі проблему використання різних платформ дистанційного навчання досліджували О. Бунятян, В. Валуйський, П. Голобородько, І. Коржик, О. Кузнєцов, А. Лавренюк, I. Малюкова, М. Львов та ін. Однак, поза увагою дослідників залишилися проблеми використання цифрових освітніх платформ у професійній підготовці майбутніх викладачів 3ВО, що зумовлює актуальність теми наукової публікації.

Мета дослідження - особливості використання цифрових освітніх платформ у процесі підготовки майбутніх викладачів ЗВО.

Результати дослідження. Наш науковий пошук засвідчив, що для організації освітнього процесу та керування ним існує велика кількість платформ. Розглянемо найбільш поширені із них.

Платформа Moodle - це безкоштовна система для розміщення електронних матеріалів (лекцій, презентацій та ін.) для самостійного вивчення та підтримки проведення лекцій / семінарів в онлайн-режимі; проведення тестування (проміжних, підсумкових); організації комунікації зі студентами (чат, форум) [4]. Аналогічний функціонал мають платформи: MaxSite CMS, Drupal, Joomla, (системи мають українську локалізацію); OLAT; Interact; Docebo; Wordcircle; e107; RedDot; Microsoft CMS; Rhythmyx; Documentum; Open pages; Chrystal Software; Viagnette; CyberTeams; Blue Martini; Tikiwiki CMS Groupware [7]

Zoom - сервіс для проведення онлайнконференцій та відеозв'язку. Дає можливість планувати і організовувати відеоконференції для проведення лекцій, консультацій та семінарів для різної кількості користувачів в онлайн-форматі. Інтегрована з DistEdu, що дозволяє автоматично додавати відеоконференції до календаря та відповідно інформувати студентів, а також записувати, зберігати і поширювати відеоконтент при потребі. Використовується безкоштовна 40хвилинна версія Zoom або платна Zoom of Education [2, 23].

Для всіх власників особистого облікового запису Google створено платформу Google Classroom - це хмарно орієнтована платформа, що об’єднує в собі: Google Docs, Sheets, Slides, Forms для створення текстів і презентацій, редагування файлів у хмарному сховищі; Google Drive для зберігання й одночасного доступу до файлів; Google Календар для розкладу; Google Meet для проведення відеоконференцій; Google Чат для спілкування; Gmail для листування. Google Classroom $\epsilon$ зручною, гнучкою, інтерактивною і персоналізованою платформою для навчання, оскільки дозволяє публікувати і оцінювати завдання, організувати спільну роботу і ефективну інтеракцію всіх учасників процесу, створювати навчальні курси, ділитися освітніми матеріалами, роздавати завдання і коментувати роботи студентів в одному сервісі $[2,23]$.

Відеоконференції можна проводити також за допомогою Microsoft Teams, Google Meet, Skype, Cisco WebEx та ін.

Discord - це програма, яка дозволяє спільноті швидко комунікувати з допомогою текстових або голосових повідомлень. Додаток розробили для онлайн-ігор, у яких гравцям треба оперативно обмінюватися думками та стратегіями. Однак сьогодні додаток активно використовують у дистанційному навчанні. Перевага Discord y тому, щзо вона організовує всі можливості для комунікації в одному місиі.

Є ресурси, які допомагають створити презентації інфографіку та графічний дизайний і які можна вважати альтернативою Power Point.

Canva - кросплатформний безкоштовний графічний редактор 3 додатковими платними послугами. Надає доступ до вбудованої бібліотеки шаблонів, стокових фотографій, векторних зображень, графіки та шрифтів. Шаблони в Canva мають унікальний дизайн і складаються 3 декількох елементів: фон, текст, додаткове зображення і ін. Особливістю Canva $є$ робота в реальному часі кількох користувачів над одним або кількома проєктами; створення та редагування GIF-анімацій та відео; онлайнпублікація готових проєктів; експорт робіт у різних форматах; обробка фотокарток за допомогою 


\section{ВИКОРИСТАННЯ ЦИФРОВИХ ОСВІТНІХПЛАТФОРМ У ПРОЦЕСІ ПІДГОТОВКИ МАЙБУТНІХ ВИКЛАДАЧІВ ЗВО}

фільтрів і ручних налаштувань зображення; створення графіків і діаграм для звітів; додавання текстури до фонового зображення тощо.

Calameo - сервіс для створення інтерактивних публікацій (у формі журналів, брошур, каталогів, звітів тощо). Причому в інтерактивного документа є додаткові функції: гортати сторінки, позначати цікаві моменти та ін.

Crello - графічний онлайн-редактор, який пропонує понад 10000 шаблонів у безкоштовному доступі для створення зображень для соціальних мереж, рекламних банерів, плакатів, заголовків та ін. Має платну версію 3 розширеними можливостями.

Desygner - онлайн-редактор для створення презентацій, рекламних матеріалів, постів для соціальних мереж та ін. [1].

Prezi.com - це веб-сервіс, за допомогою якого можна створити інтерактивні мультимедійні презентації з нелінійної структурою. Робота вебсервісу Prezi.com заснована на технології масштабування (наближення і віддалення об'єктів). На відміну від класичної презентації PowerPoint або OpenOffice Impress, де презентація розбиті на слайди, в Prezi основні ефекти пов'язані не 3 переходом від слайду до слайду, а зі збільшенням окремих частин одного й того ж слайду.

Beautiful.ai - англомовний сервіс для створення презентацій, який працює на базі технологій штучного інтелекту. Сервіс самостійно адаптує контент на слайдах під вибраний формат, допомагає додати анімацію графіків і переходів, а також репрезентує відповідні шаблони [3, 155-156].

Easel.ly - онлайн-інструмент, що дозволяє створювати інфографіку та візуалізувати дані 3 допомогою різноманітних іконок у вигляді рухомих чоловічків, ліній та діаграм.

Genially - онлайн-інструмент 3 широким вибором візуальних ефектів та анімацій для створення презентацій, інтерактивних зображень, інфографіки та ін.

Маємо і сервіси для створення діаграм та графіків:

Dygraphs - інструмент для візуалізації великої кількості даних, що дозволяє створювати інтерактивні, масштабовані діаграми.

Excel - програма для роботи з електронними таблицями, $є$ складовою пакету Microsoft Office. Вона необхідна для проведення розрахунків, аналізу даних, прогнозування, складання графіків, таблиць і діаграм, обчислення простих і складних функцій.

Infogr.am - cервіс для створення інтерактивної візуалізації. Містить понад 30 типів діаграм і шість тем оформлення. Аналогічною за функціоналом є платформа Plotly, яка працює з JavaScript, Python, R, Matlab, Excel.

Fusiontables - інструмент Google для створення діаграм, графіків і карт. Допомагає збирати, візуалізувати дані та показувати їх на сайті [1].

Відеолекції з можливістю накладати на відео тести або інші завдання забезпечують такі сервіси, як TEDEd, FlipGrid [5].

Також є ресурси, які допомагають створити тексти і завдання та здійснити перевірку знань:

Kahoot (https://kahoot.com) - платформа для створення вікторин, тестів, дидактичних ігор, а також для перевірки знань.

Quizel (https://quizlet.com) - безкоштовний онлайн-сервіс, що дає змогу студентам вивчати нові терміни за допомогою спеціальних інструментів і навчальних ігор, представлених на цьому ресурсі. У викладача $є$ можливість створювати і застосовувати в навчанні так звані флеш-картки, що виступають базисним компонентом навчального модуля, який складається з набору карток за різними темами. На ресурсі представлені мільйони готових модулів. Викладач може підібрати потрібний модуль за допомогою пошуку і безкоштовно використовувати контент, створений іншими користувачами.

Learningapps (https://learningapps.org) онлайновий сервіс, який $є$ конструктором для розробки та зберігання різноманітних інтерактивних завдань. Допомагає перевірити i закріпити знання в ігровій формі, що сприяе формуванню у студентів пізнавального інтересу.

Linoit (http://en.linoit.com) - віртуальна онлайн дошка спільного використання. Linoit дає змогу розміщувати стікери 3 необхідними записами, картинки (фотографії), відео, посилання на файли різних форматів. Всі об'єкти, розміщені на цій дошці, можуть редагувати не тільки викладач, але й студенти. Якщо необхідно, то можна надати доступ до дошки всім студентам і працювати колективно [3, 156-157].

Classtime - платформа для створення інтерактивних навчальних додатків, яка дозволяє організовувати моніторинг освітнього процесу і реалізовувати індивідуальний підхід щодо студентів. Принцип роботи такий: викладач розробляє інтерактивний матеріал з певної теми, студенти отримують доступ до цього матеріалу розпочинають роботу, викладач у режимі реального часу відстежує виконання роботи кожним студентом $[2,24]$.

Online test pad Ta Triventy.com - 


\section{ВИКОРИСТАННЯ ЦИФРОВИХ ОСВІТНІХПЛАТФОРМ У ПРОЦЕСІПІДГОТОВКИ МАЙБУТНІХ ВИКЛАДАЧІВ ЗВО}

безкоштовні багатофункціональні конструктори кросвордів, логічних ігор, навчальних та психологічних тестів, опитувань.

Quizlet.com - безкоштовний сервіс, який допомагає легко запам'ятовувати будь-яку інформацію, котру можна представити у вигляді навчальних карток.

Flippity - колекція цифрових інструментів, які допоможуть створити інтерактивні вправи та завдання в ігровій формі [5].

Розроблено і сервіси для створення підбірок матеріалів:

Padlet - віртуальна цифрова стіна, на якій можна розміщувати документи, покликання, відеоролики, зображення тощо. Можлива спільна робота на стіні кількох учасників. Стіну Padlet можна використовувати для розміщення матеріалів, які здобувачі освіти повинні опрацювати дистанційно.

Wakelet - сервіс для створення підбірок файлів, зображень, гіперпокликань, відеофільмів. Підбіркою можна поділитися через покликання, а також вбудувати в сайт чи блог.

Онлайн-дошка "Miro" - сервіс, який дозволяє взаємодіяти зі здобувачами освіти. $€$ функції: додавання зображень, відео, документів на дошку; можливості зробити замітку, намалювати фігуру, підкреслити [5].

Висновки та перспективи подальших досліджень. Таким чином, використання сервісів дистанційного навчання уможливить підвищити і вдосконалити ефективність навчального процесу у ЗВО, зробити навчальні завдання більш цікавими, різноманітними, привабливими для студентів, а головне - забезпечити основну парадигму “економіки знань” - навчання упродовж життя.

\section{ЛІТЕРАТУРА}

1. Візуалізація та графічний дизайн. URL: https://library.sumdu.edu.ua/uk/doslidnyku/ prohramne-zabezpechennia/analiz-danykh-tavizualizatsiia/vizualizatsiia-ta-hrafichnyi-dyzain.html. (дата звернення: 30.04.2021)

2. Гуревич Р.С. Інформаційно-телекомунікаційні технології в навчальному процесі та наукових дослідженнях: навч. посіб. для студ. пед. ВНЗ слухачів ін-тів післядипломної пед. освіти. Вінниця: ООО “Планер”, 2005. 366 с.

3. Лебідь О.В. Сервіси дистанційного навчання для викладачів закладів вищої освіти. Сучасна вища освіта: перспективні та пріоритетні напрями наукових досліджень: II Міжнародна науково-практична конференція студентів, аспірантів та науковців: тези доповідей,
Дніпро, 25 березня 2021 р. Дніпро: Університет імені Альфреда Нобеля, 2021. С. 154 - 159.

4. Осадча К., Осадчий В., Спірін О., Круглик В. Реалізація індивідуалізації та персоналізації навчання засобами MOODLE. Молодь і ринок, 2021. №1 (187). C. 38-43.

5. Підбірка сервісів для дистанційного навчання. URL: http://www.kdket.net.ua/files/ dystanc/3б рка \%20серв с в $\% 20$ для\% 20 дистанц йного \%20 навчання.pdf (дата звернення: 10.05.2021)

6. Стинська В.В. Основні проблеми реформування вищої освіти України у контексті Болонського процесу: збірник наукових праць. Серія: Педагогіка, психологія і соиіологія. 2008. Вип. 2. С.62-64

7. Stynska V., Kondur O. Strategies of professional preparation of the competitive specialist in the conditions of information environment. Contemporary technologies in the educational process monografia. Education in the postcoronavirus world: the place of information and innovative technologies, 2020. Publishing House of Katowice School of Technology, pp. 75-81.

\section{REFERENCES}

1. Vizualizatsiia ta hrafichnyi dyzain [Visualization and graphic]. Available at: https://library. sumdu.edu.ua/uk/doslidnyku/prohramnezabezpechennia/analiz-danykh-ta-vizualizatsiia/ vizualizatsiia-ta-hrafichnyi-dyzain.html(Accessed 30 April 2021). [in Ukrainian].

2. Hurevych, R.S. (2005). Informatsiinotelekomunikatsiini tekhnolohii v navchalnomu protsesi ta naukovykh doslidzhenniakh: navch. posib. dlia stud. ped. VNZ i slukhachiv in-tiv pisliadyplomnoi ped. osvity [Information and telecommunication technologies in the educational process and scientific research]. Vinnytsia, 366 p. [in Ukrainian].

3. Lebid, O.V. (2021). Servisy dystantsiinoho navchannia dlia vykladachiv zakladiv vyshchoi osvity [Distance learning services for teachers of higher education institutions]. Suchasna vyshcha osvita: perspektyvni ta priorytetni napriamy naukovykh doslidzhen: II Mizhnarodna naukovo-praktychna konferentsiia studentiv, aspirantiv ta naukovtsiv: tezy dopovidei, Dnipro, 25 bereznia 2021 r. - Modern higher education: promising and priority areas of research: II International scientific-practical conference of students, graduate students and scientists: abstracts, Dnipro, March 25, 2021. (pp. 154 - 159). Dnipro. [in Ukrainian].

4. Osadcha, K., Osadchyi, V., Spirin, O. \& Kruhlyk, V. (2021). Realizatsiia indyvidualizatsii ta personalizatsii navchannia zasobamy MOODLE 


\section{ОСОБЛИВОСТІ УПРАВЛІННЯ ОСВІТОЮ В ЦЕНТРАЛЬНОЕВРОПЕЙСЬКИХ КРАЇНАХ НА РЕГІОНАЛЬНОМУ І НАЦІОНАЛЬНОМУ РІВНЯХ}

[Implementation of individualization and personalization oflearning by means of MOODLE]. Youth \& market, No.1 (187). pp. 38-43. [in Ukrainian].

5. Pidbirka servisiv dlia dystantsiinoho navchannia [A selection of services for distance learning]. Available at: http://www.kdket.net.ua/files/dystanc/ Zb_rka\% 20serv_s_v \%20dlia\% 20dystants ynoho\%20navchannia.pdf [in Ukrainian] (Accessed 10 May 2021).

6. Stynska, V.V. (2008). Osnovni problemy reformuvannia vyshchoi osvity Ukrainy u konteksti Bolonskoho protsesu: zbirnyk naukovykh prats [The main problems of reforming higher education in Ukraine in the context of the Bologna process]. Series: Pedagogy, psychology and sociology. Vol. 2. pp.62-64. [in Ukrainian].

7. Stynska, V.V. \& Kondur, O. (2020). Strategies of professional preparation of the competitive specialist in the conditions of information environment. Contemporary technologies in the educational process monografia. Education in the postcoronavirus world: the place of information and innovative technologies, Publishing House of Katowice School of Technology, pp. 75-81. [in English].

Стаття надійшла до редакції 14.04.2021

УДК $378 ; 371.134 ; 373.5 .016(043.3)$

DOI:

Оксана Товканець, доктор педагогічних наук, доиент, доцент кафедри загальної педагогіки та педагогіки вищоої школи, ДВНЗ “Ужггородський національний університет”

\section{ОСОБЛИВОСТІ УПРАВЛІННЯ ОСВІТОЮ В ЦЕНТРАЛЬНОЄВРОПЕЙСЬКИХ КРАЇНАХ НА РЕГІОНАЛЬНОМУ І НАЦІОНАЛЬНОМУ РІВНЯХ}

У статті схарактеризовано особливості управління освітою в центральноєвропейських краӥнах на регіональному і національному рівнях. Обтрунтовано нормативнозаконодавчу базу щуодо управління освітою в Болгарії, Словенії, Словаччині, Чехії. Акцентовано увагу на особливості управління освітою в ичих країнах на національному рівні, суть якої полягає в реалізації урядом державної політики у сфері освіти; прогнозуванні і плануванні заходів тощзо. Визначено, щуо у європейському освітньому середовищі управлінські структури чітко розмежовані на рівні: національний, регіональний, рівень окремої освітньої установи. Наголошено, щуо основними напрямами розвитку ефективності системи управління є забезпечення якості освіти.

Ключові слова: управління освітою; чентральноєвропейські краӥни; освіта Болгарії; освіта Словенї; освіта Словаччини; освіта Чехї.

Jim. 14.

Oksana Tovkanets, Doctor of Sciences (Pedagogy), Associate Professor, Associate Professor of the General Pedagogy and Higher School Pedagogy Department, SHEE "Uzhhorod National University"

\section{PECULIARITIES OF EDUCATION MANAGEMENT IN CENTRAL EUROPEAN COUNTRIES AT REGIONAL AND NATIONALLEVELS}

The article describes the features of education management in Central European countries at the regional and national levels. The normative legal base on education management in Bulgaria, Slovenia, Slovakia, and the Czech Republic is substantiated. An attention is focused on the peculiarities of education management in these countries at the national level, the essence of which is the government's implementation of the state policy in the field of education; forecasting and planning activities related to the development of education through the preparation of long-term programs and operational plans; organization and coordination of the work of administrative units and educational institutions; monitoring activities at all levels in different types of schools, approval of standard school documentation. It is determined that in the European educational environment management structures are clearly demarcated at the level - national, regional, level of an individual educational institution. The educational systems of Central European countries and the modern system of management and administration of educational institutions are aimed at ensuring a balanced policy in the field of education, creating appropriate infrastructures and finding the means necessary for the successful functioning of educational systems; to ensure the fundamental right of every person regardless of his age, gender, social status; to create a universal system of criteria and recommendations for the development of education, content and teaching methods, research and pedagogical 